\title{
DIE LIED VAN HANNA: 'n DIGTERLIKE BOUSTEEN
}

\section{J H POTGIETER}

\begin{abstract}
THE SONG OF HANNAH: A POETICAL COMPONENT.

The prayer of Hannah is a beautiful poem, but has not received the attention as a poem which it rightfully deserves. Various aspects such as its similarity with Psalm 113, its textcritical difficulties and the secondary nature in the context of the book have previously been discussed, but unfortunately not enough thought has been given to its poetical character. This article investigates the intratextual relationships of the poem. This is done in order to illustrate that it is possible to reach a better understanding of the poem itself as well as to determine its contribution to the message of the larger context of the book.
\end{abstract}

'n Opvallende kenmerk van die bespreking in die literatuur oor hierdie gebed in I Samuel 2:1-10 is die feit dat allerlei aspekte behalwe die intrinsieke waarde van die gedig onder bespreking gekom het. So het Willis ${ }^{1}$ en Freedman ${ }^{2}$ die invloed wat ekstratekstuele gegewens soos onder andere Psalm 113 op die interpretasie van hierdie gebed uitgeoefen het, ondersoek. Calderone ${ }^{3}$, Grill ${ }^{4}$ en Thomas ${ }^{5}$ daarenteen, het hulle op sekere tekskritiese lesings toegespits. Andere soos Stoebe ${ }^{6}$ en Klein ${ }^{7}$ behandel hierdie gedeelte vanuit die perspektief dat dit 'n sekondêre toevoeging is en as gevolg van toevallige ooreenkomste met die omstandighede van Hanna (soos wat dit in vers $5 \mathrm{c}$ en $5 \mathrm{~d}$ vergestalt is) hier ingevoeg is. Van $\mathrm{Zyl}^{8}$ aanvaar die sekondêre aard van die gebed met die voorbehoud dat dit spesiaal aangepas is vir Hanna se omstandighede. Oor die algemeen word die gedig dus op ' $n$ ad hoc-grondslag behandel waarmee nie alleen die skeppingsvermoë en literêre aanvoeling van die outeur/redaktor gruwelik misken word nie, maar die inherente kommunikasiemoontlikhede van die gedig ook glad nie ontgin word nie.

Die uitgangspunt van hierdie artikel daarenteen is dat die gebed as ' $n$ bousteen met bepaalde funksies binne die verhaaleenheid of -eenhede wat dus tot die betekenis daarvan bydra - beskou moet word. Voordat hierdie gebed, as afgeronde poëtiese eenheid, se funksie binne die groter eenheid bepaal kan word, is dit noodsaaklik om eers die gedig self te analiseer en die betekenis daarvan vas te stel. Uiteraard kan binne hierdie kort bestek slegs aandag aan die intratekstuele relasies binne die gedig gegee word en kan slegs sydelings verwys word na vrae soos die invloed van ekstratekstuele relasies op die verstaan van die poëtiese gedeelte of 

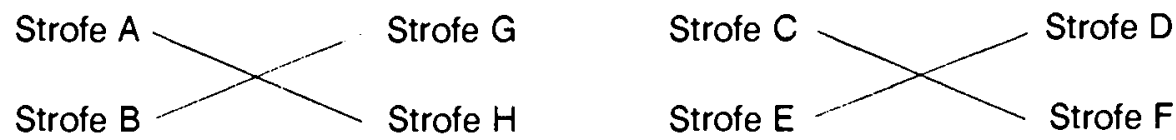

Hieruit is dit duidelik dat die gedig sowel struktureel as inhoudelik uit twee dele bestaan wat ' $n$ spieëlbeeld van mekaar vorm. Volgens hierdie samestelling lê die swaartepunt by die twee middelste strofes wat uit die antitetiese parallelismes bestaan. Hierdie antiteses word egter op so 'n wyse ingespan dat die metafoor waarmee die gedig begin en eindig daarmee onderbou word. Deur middel van dié teenstellings word geillustreer hoe Jahwe die bidder in 'n magsposisie plaas. Diegene wat selfgenoegsaam is en op hulle eie vermoëns vertrou, sal deur Jahwe omvergegooi word, maar dié wat op Hom vertrou sal $\mathrm{Hy}$ in 'n posisie van oonwinning plaas. Die spieëlbeeldstruktuur van die gedig kan skematies soos volg voorgestel word:

Stansa I

Strofe A (inleiding + horingmetafoor)

Strofe B (tristige - onvergelykbaarheid van Jahwe)

Stansa II

Strofe $C$ (vermaning teen hoogmoed) Strofe D (3 antiteses)

Stansa III

Strofe $E$ (2 antiteses)

Strofe $F$ (antitese + verheffing van die geringe)-

Stansa IV

Strofe $G$ (tristige - onvermoë van die mens)

Strofe H (Slot + horingmetafoor)

Bogenoemde waarneming word bevestig deur die wyse waarop ekstra patroonvorming as dominante kommunikasiemiddel in hierdie gedig gebruik word. Daarmee word die effek van vooropstelling bereik. Wanneer in aanmerking geneem word dat hierdie teenstellings ' $n$ bepaalde patroon vertoon binne die drie versreëls van strofe $D$, is dit duidelik dat die laaste versreël die klimaks van hierdie reeks vorm. Die patroon bestaan daaruit dat die negatiewe element in die eerste twee versreëls elke keer eerste genoem word en dan deur die positiewe element gevolg word.

By die derde versreël word die orde egter omgekeer en die positiewe element word eerste genoem. In stansa III is daar ook drie stelle antiteses, maar omdat die teenstelling inherent in elke versbeen is, word deur middel van parallelismes in versreëls 8 en 9, 'n verdubbeling bewerkstellig. Weer eens is daar in die derde versreël, naamlik versreël 10, 'n verandering in 
Toe het Hanna gebid:

I A 13 My hart is bly in die Here

3 my horing is hoog in die Here.

My mond is wyd oop oor my vyand,

want ek is verheug oor $u$ redding.

B 33 Daar is geen heilige soos die Here nie. 2 a $\mathrm{Ja}$, daar is niemand buiten u nie.

Daar is geen rots soos ons God nie.

Moenie hoogmoed vermeerder deur hoogmoedig te praat nie,

3 moenie verwaandheid uit julle mond laat uitgaan nie,

54 want die Here is 'n God van kennis en word dade nie getoets nie? maar die wat honger was, word vet van kos. maar die een met baie kinders kwyn weg. Hy verneder, ook gee Hy aansien. $\mathrm{Ja}$, aan die Here behoort die pilare van die aarde, en op hulle het Hy die wêreld gevestig.

$$
\text { uit die hemel donder Hy op hom. }
$$

\section{BESPREKING.}

Die gedig bestaan uit vier stansas wat met die Romeinse syfers I, II, III en 
IV in die heel linkerkantste kolom aangedui word. Dit word weer deur die letters A, B, C ens., gevolg om die strofes wat die onderafdelings van die stansas vorm, aan te dui. Aangesien elke stansa uit twee strofes bestaan, is daar agt strofes in die gedig. Elke strofe bestaan weer uit verskillende versreëls wat deur die nommers 1, 2, 3 ensovoorts, verteenwoordig word. Die laaste reeks nommers links van die teks dui die metrum van elke versbeen aan. Regs van die teks staan die versnommers soos dit in die Masoretiese teks voorkom, terwyl die individuele versbene met $a, b$ en $c$ gemerk is. Met die soliede verbindingslyne word die strukturele verbande skematies weergegee en die stippellyne dui die makroverbande tussen die ooreenstemmende inhoudselemente aan.

Bartelmus $^{9}$ wys op die twee teenoorstaande benaderings waarin die gebed enersyds as 'n strofiese gedig behandel en andersyds as 'n struktuurlose skepping wat uit gelykvormige verse bestaan, beskou word. Alhoewel hyself nie ' $n$ strofiese indeling volg nie, kies hy ook nie vir totale struktuurloosheid nie. Op grond van die tydsaspek van die verbale vorme wat hy as struktuurprinsipe gebruik, verdeel hy die gedeelte in twee dele, naamlik verse 1-3 en verse 4-10. Diegene soos Ritterspach ${ }^{10}$, De Boer ${ }^{11}$ en Van der Meer ${ }^{12}$ wat wel 'n strofiese indeling van die gedig maak, verdeel dit in drie strofes wat onderskeidelik uit verse 1-3, 4-8 en 9-10 saamgestel is.

My eerste stansa, wat rofweg met bovermelde eerste strofe ooreenstem, sluit egter aan die einde van vers 2 af. Die redes daarvoor is die volgende. Eerstens vorm volgens Watson ${ }^{13}$ 'n tristige soos wat in vers 2 voorkom dikwels ' $n$ logiese en strukturele strofiese eenheid. Tweedens sluit hierdie strofe formeel en inhoudelik baie nou by die eerste strofe aan waar daar oonwegend van Jahwe in die derde persoon gepraat word. Aangesien dit primêr in hierdie eerste twee strofes om die sprekende subjek en sy verhouding met Jahwe gaan, is daar ' $n$ duidelike breuk voor vers 3 waar iemand anders in die tweede persoon meervoud aangespreek word.

Behalwe vir die persoonsverandering, is die negatiewe bevel waarmee vers 3 begin ook ' $n$ sterk aanduiding dat 'n nuwe stansa hier begin. Stansa II bestaan uit twee strofes wat as gevolg van die reeks antitetiese parallelismes wat van vers 4 af voorkom, duidelik onderskeibaar is. Strofe $C$ bestaan uit die hele vers 3 , want die parallelle versbene $3 a$ en $3 b$ word deur die daaropvolgende versbene $3 c$ en $3 b$ gemotiveer. Tekskrities is daar geen rede waarom die teks op grond van ander manuskripte geëmendeer hoef te word nie, aangesien dit wel sin maak soos wat dit hier staan. By $3 \mathrm{~b}$ het daar delesie van die partikel 'al plaasgevind en by $3 \mathrm{~d}$ kan die $w^{\ominus} \mid o^{\prime}$ as 'n negatiewe vraagpartikel gelees word. Alhoewel die reeks antiteses wat by vers 4 begin, tot by $8 b$ aanhou, strek strofe $D$ slegs 
tot aan die einde van $5 \mathrm{~d}$. Twee redes kan hiervoor aangevoer word, naamlik dat die subjek Jahwe eksplisiet vanaf vers 6 genoem word en dat die antiteses in verse 4 en 5 tussen die onderiinge versbene gevorm is, terwyl dit by verse 6 en 7 intern in elke versbeen is. Die tekskritiese probleem in vers $5 b$ is myns insiens bevredigend deur Calderone ${ }^{14}$ en Thomas ${ }^{15}$ opgelos. Hierdie oplossing word in my Afrikaanse vertaling gereflekteer.

Stansa III bevat ook twee strofes. Hoewel vers $8 \mathrm{a}$ en $8 \mathrm{~b}$ nog voortgaan met die teenstellings, verander die patroon weer terug na antiteses tussen die versbene en boonop brei die res van die vers uit op die betrokke teenstelling. Daarom begin strofe $F$ by vers 8 terwyl $E$ verse 6 en 7 insluit.

Die tristige wat in vers 9 voorkom, vorm nie alleen strofe $G$ nie, maar is ook die begin van stansa IV. Strofe $H$ bestaan uit vers 10 en sluit die gedig af deur bepaalde uitsprake oor Jahwe te maak. Dit sluit onder andere die metafoor "en $\mathrm{Hy}$ verhef die horing van sy gesalfde" in. Indien die $k^{e}$ tiblesing in versbene 9a en $10 \mathrm{a}$ gevolg word, lewer dit die minste probleme en kan die oënskynlike derdepersoon meervoudsuitgang as 'n derdepersoon enkelvoud verbale suffiks gelees word.

Wat is nou die wins wat hierdie indeling bo ander indelings bied? Behalwe dat dit ' $n$ meer genuanseerde beeld van die gedig vertoon, is dit ook myns insiens 'n meer korrekte weergawe van die struktuur wat weer op sy beurt van belang is vir die betekenis. Hierdeur het 'n interessante patroon waarop die verskillende strofes met mekaar korreleer, na vore gekom. Die twee strofes van stansas I en IV korreleer op 'n chiastiese wyse met mekaar. Dus verbind strofes $A$ en $\mathrm{H}$ met mekaar terwyl strofes $B$ en $\mathrm{G}$, wat altwee uit tristiges bestaan, weer op mekaar gerig is. Strofe $A$ begin met die metafoor "my horing is hoog in die Here" terwyl strofe $\mathrm{H}$ met dieselfde metafoor afsluit. Deur middel van hierdie metafoor, wat 'n magsposisie aandui, word 'n inclusio tussen die twee strofes gevorm. 'n Soortgelyke chiastiese patroon kom ook by die strofes van die twee middelste stansas voor. Gevolglik word strofe $\mathrm{C}$ en $\mathrm{F}$ met mekaar verbind omdat albei van hulle bepaalde uitsprake, wat deur die partikel $k \hat{i}$ ingelei word, oor Jahwe maak. Verder is daar die teenstelling tussen die vermaning teen hoogmoedigheid in strofe $C$ en die verheffing van die geringe in strofe $F$. Die middelste twee strofes, $D$ en $E$, bevat die reeks antiteses, maar verskil tog van mekaar omdat die antiteses in strofe $D$ tussen versbene bestaan en in die strofe $E$ inherent aan elke versbeen is. Bogenoemde chiasmes kan grafies op die volgende wyse weergegee word: 
die funksie van die gedig binne die verhaalopset.

Die volgende werkswyse sal in die bespreking van die gebed in 1 Samuel 2:1-10 gevolg word. Aangesien dit ' $n$ poëtiese gedeelte is, word eers ' $n$ stigometriese analise van die Hebreeuse teks gemaak. Dit behels ' $n$ verdeling van die gedig in versbene, versreëls, strofes en stansas. In die Afrikaanse vertaling wat daarop volg, is getrag om die Hebreeuse konstruksies so getrou as moontlik weer te gee en die vertaling is dus op dieselfde stigometriese wyse ingedeel. Daarna volg die motivering en bespreking van die analise. Tydens hierdie bespreking sal ook aan die enkele tekskritiese probleme aandag gegee word. Laastens word na die kommunikatiewe funksie van die aangewese poëtiese kunsgrepe of konvensies en hulle onderlinge relasies gevra om so by ' $n$ interpretasie van die boodskap van hierdie gedeelte uit te kom.

STRIGOMETRIESE ANALISE.

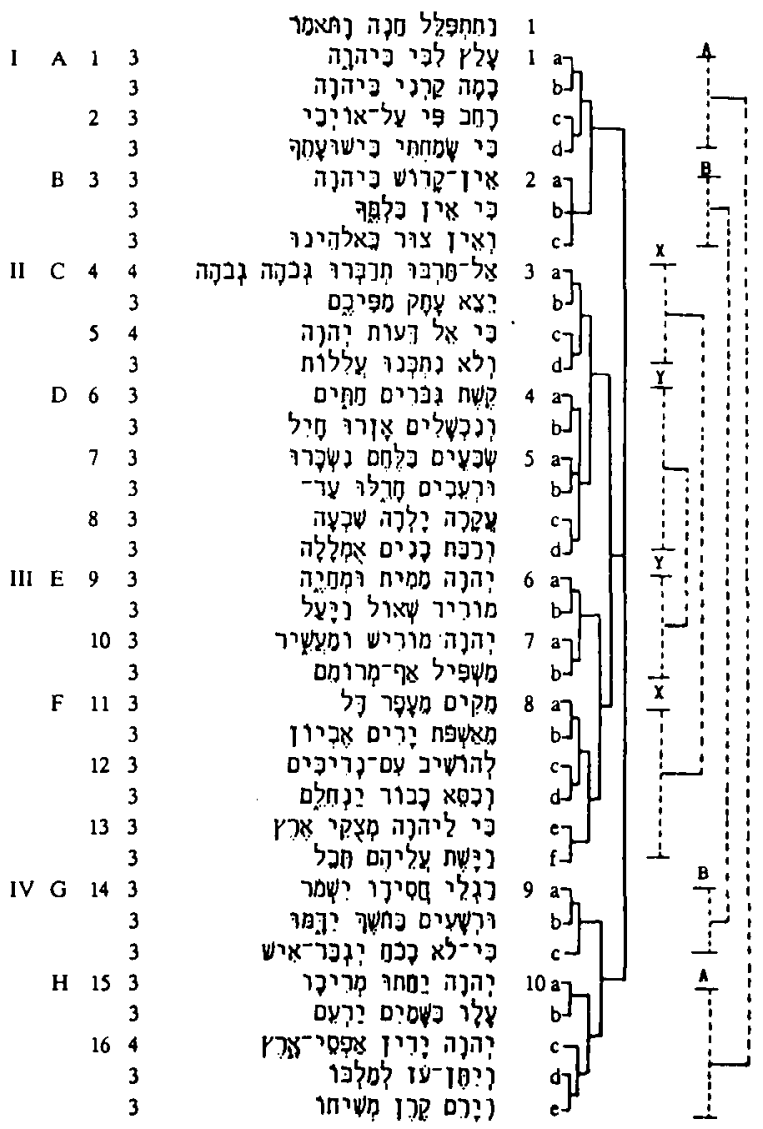


die patroon aangebring. Die verandering bestaan daarin dat in hierdie versreël daar geen teenstelling tussen negatief en positief voorkom nie. maar daar word slegs 'n positiewe stelling gemaak wat sterk uitgebou word. Net soos by die vorige strofe bring hierdie verandering in die patroon vooropstelling teweeg.

Uit die voorafgaande is dit duidelik dat die swaartepunt van die gedig nie alleen in die middelste twee strofes met hul reeks antiteses gesoek moet word nie, maar dat die derde versreël van elkeen van hierdie strofes telkens besondere klem dra. Binne die gedig is hierdie versreël in die besonder van toepassing op die omstandighede van Hanna, omdat die omkering van haar kinderloosheid en haar vernedering daardeur belig word. Deur die antiteses as dominante teksstrategie te gebruik, word die metafoor nie alleen verduidelik nie, maar word die boodskap van die gedig op 'n artistieke wyse belig.

Die gedig is dus nie alleen 'n getroue refleksie van gebeure wat Hanna se lewe raak nie, maar dui ook op 'n lewensfilosofie wat vir die res van die boek geld. Saam met die ander teenstellings en die metafoor wat daardeur onderbou word, dui dit op 'n filosofie of beskouing wat ook op die boek as geheel betrekking het. Nie alleen Hanna se posisie nie, maar ook dié van Samuel en ook later dié van Dawid word deur Jahwe ten goede verander terwyl al drie se teenstanders se magsposisie omgekeer is.

Omdat die poëtiese aard van die gebed vir onmiddellike vooropstelling sorg, skep dit geleentheid vir die outeur \redaktor om 'n bepaalde teologiese beginsel waarop sy geskiedenis berus, daar te stel.

\section{NOTAS}

1 JT Willis, "The song of Hannah and Psalm 113", CBQ vol 35 (1973), 139-154.

2 D N Freedman, "Psalm 113 and the song of Hannah", in Pottery, poetry and prophecy, Winona Lake 1980, 243-261.

3 P J Calderone, "HDL-II in poetic texts", CBQ vol 23 (1961), 451-460.

4 S Grill, "Die alten Versionen und die Partikeln lo',18,10, 1 ", $B Z$ vol 1 (1957), 277-281.

5 D W Thomas, "Some observations on the Hebrew root hdl", in VT SUP 4 Congress Volume: Strasbourg, Leiden (1957), 8-16.

6 H J Stoebe, Das erste Buch Samuelis, Gütersloh 1973, 107.

7 RW Klein, 1 Samuel, (WBC), Waco 1983, 14-15.

8 A H Van Zyl, 1 Samuel, Nijkerk 1988, 41-42.

9 R Bartelmus, "Tempus als Strukturprinzip", BZ vol 31 (1987), 15-35. 
10 A D Ritterspach, "Rhetorical criticism and the song of Hannah", in Rhetorical Criticism (Essays in honor of James Muilenburg, Edited by $\mathrm{J} J$ Jackson and M Kessler), Pittsburg 1974, 68-74.

11 P A H De Boer, "Einige Bemerkungen und Gedanken zum Lied in 1. Samuel 2, 1-10," in Beiträge zur alttestamentliche Theologie (Edited by $H$ Donner and $R$ Smend), Göttingen 1977, 53-59.

12 W van der Meer, "De lofzang van Hanna, 1 Samuel 2, 1-10", GTT vol 7 (1976), 193204.

13 W G E Watson, Classical Hebrew poetry: a guide to its techniques, Sheffield 1986, 164.

14 Calderone, a.w.,454.

15 Thomas, a.w. 